\title{
Perinatal Subependymal Hemorrhage with Intraventricular and Intracerebral Extension
}

National Cancer Institute

\section{Source}

National Cancer Institute. Perinatal Subependymal Hemorrhage with Intraventricular and Intracerebral Extension. NCI Thesaurus. Code C103187.

A hemorrhage that involves the subependymal region, the lateral cerebral ventricles and the brain tissue occurring around the time of birth. 